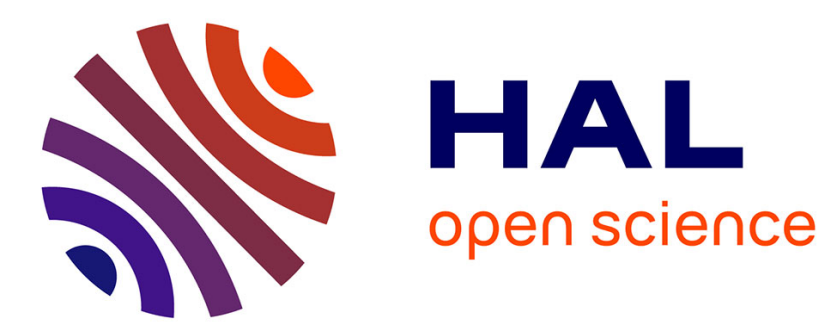

\title{
Experimental analysis of CFRP laminates subjected to compression after edge impact
}

Benjamin Ostré, Christophe Bouvet, Clément Minot, Jacky Aboissière

\section{To cite this version:}

Benjamin Ostré, Christophe Bouvet, Clément Minot, Jacky Aboissière. Experimental analysis of CFRP laminates subjected to compression after edge impact. Composite Structures, 2016, 152, pp.767778. 10.1016/j.compstruct.2016.05.068 . hal-01828742

\section{HAL Id: hal-01828742 \\ https://hal.science/hal-01828742}

Submitted on 3 Jul 2018

HAL is a multi-disciplinary open access archive for the deposit and dissemination of scientific research documents, whether they are published or not. The documents may come from teaching and research institutions in France or abroad, or from public or private research centers.
L'archive ouverte pluridisciplinaire HAL, est destinée au dépôt et à la diffusion de documents scientifiques de niveau recherche, publiés ou non, émanant des établissements d'enseignement et de recherche français ou étrangers, des laboratoires publics ou privés. 


\section{Open Archive TOULOUSE Archive Ouverte (OATAO)}

OATAO is an open access repository that collects the work of Toulouse researchers and makes it freely available over the web where possible.

This is an author-deposited version published in: http://oatao.univ-toulouse.fr/ Eprints ID: 15958

To link to this article: DOI: $10.1016 / j . c o m p s t r u c t .2016 .05 .068$

URL: http://dx.doi.org/10.1016/j.compstruct.2016.05.068

To cite this version: Ostré, Benjamin and Bouvet, Christophe and Minot, Clément and Aboissière, Jacky Experimental analysis of CFRP laminates subjected to compression after edge impact. (2016) Composite Structures, vol. 152. pp. 767-778. ISSN 0263-8223

Any correspondence concerning this service should be sent to the repository administrator: staff-oatao@listes-diff.inp-toulouse.fr 


\title{
Experimental analysis of CFRP laminates subjected to compression after edge impact
}

\author{
Benjamin Ostré ${ }^{\mathrm{a}}$, Christophe Bouvet ${ }^{\mathrm{a}, *}$, Clément Minot $^{\mathrm{b}}$, Jacky Aboissière ${ }^{\mathrm{b}}$

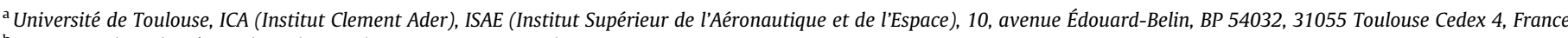 \\ ${ }^{\mathrm{b}}$ SOGETI High Tech, Aéropark, 3 chemin de Laporte, 31300 Toulouse, France
}

Keywords:

Edge impact

Compression after impact

Damage tolerance

\begin{abstract}
A B S T R A C T
Composite structures are particularly vulnerable to impact which lowers drastically theirs residual strength. In particular, the edge impact on composite stiffener is known as a critical factor on the loss of residual compression strength. At the same time, manufacturing of stiffened panels and achievement of experimental tests, of edge impact and compression after edge impact (CAEI) with stiffened panel, are particularly complex and costly. Then an experimental test set up has been designed to easily study the edge impact and the CAEI without complex specimen. It avoids the complex manufacturing of stiffener panels and avoids the use of high capacity machine. The mean goal is to define a new design method to improve the edge impact damage tolerance.

Then experimental analysis of CAEI has been carried out on carbon fibre reinforced plastic (CFRP) laminates. This paper presents these results in order to determine the residual properties of the structure and to elaborate the failure scenario. It seems that a propagation of a compressive fibre failure plays a major role in the mechanisms that drives the laminate residual strength after edge impact. The good agreement of an open hole model with point stress approach seems to confirm the major role of the compressive fibre failure in the final failure.
\end{abstract}

\section{Introduction}

Composites are widely used in the aeronautical field due to their high specific stiffness and strength, corrosion resistance and fatigue performance. Unfortunately, the aeronautical composite structures could be significantly damaged by foreign tools during manufacturing or maintenance operations and the damage occurring might remain undetected by visual inspection $[1,2]$. Aeronautical industry certification needs the proof of the impact resistance depending upon the impact damage detectability of these structures, which is known as the damage tolerance concept [3]. Moreover the composite mechanical behaviour is very complex to deal with. In particular, the damage prediction remains challenging [4,5]. Then more knowledge seems necessary to better understand the impact damage, the damage developing during the residual strength test and the effect of the impact damage on the residual strength.

Many studies have been carried out on composite skin and panel impact issues, both theoretically and experimentally, and impact and compression after impact (CAI) damage scenarios are now fairly well developed [6-10]. However, if the focus is shifted from skin to

\footnotetext{
* Corresponding author.

E-mail address: christophe.bouvet@isae.fr (C. Bouvet).
}

edge, then there seems a lack of knowledge regarding, in particular, the residual strength. To the author's knowledge, only a few researches have been conducted in this regard [11-13] which elaborate compression after edge impact (CAEI) mechanisms and show that composite structures are particularly vulnerable to edge impact.

For example free edge composite stringers of an airplane's centre wing box are strongly loaded and are designed to resist to buckling and to keep the structure safe, but if a tool drops on a stringer edge during the plane's maintenance, its residual properties can be drastically reduced [3,11,14]. Improvement of the edge impact damage tolerance could be made by defining the CAEI damage scenario.

The current edge impact detectability threshold criterion for aeronautics is driven by the dent depth and the crack length. When the impact indentation is smaller than the barely visible impact damage (BVID) and the crack length less than a given threshold value, the structure has to support the extreme loads that it is subjected to. However, if the damage is detectable, i.e. when the impact indentation is bigger than the BVID or the crack length higher than a given threshold value, a repair or change of the structure must be considered [3]. 
Even if the CAI of skin panels has been studied by a lot of authors [6-10], the scenario of the final failure is not so clear. For some authors, the buckling of the plies, delaminated during the impact, is responsible of the final failure and then drives the residual strength of the structure [1]. At the beginning of the CAI test, homogeneous compression is observed, followed by a slight increase of the structure thickness due to delamination propagation, and finally buckling leads to final failure. For example, in this study [13], Li and Chen agree that the delamination is a critical factor to the loss of stability of the laminate during the CAI test and lowers residual strength.

At the same time, a strain (or stress) concentration is observed in the boundary of the damage area, especially in the impacted side. When the strain concentration reaches the compression failure strain, a crack propagates, leading to the structure final failure (Fig. 1). For Bouvet and Rivallant [15], the crack starting zone is located in the impacted side and matches with the beginning of the first delaminated interface. This scenario seems particularly clear for highly orientated stacking sequence [15].

This idea is also proposed by Chen et al. $[16,17]$ who indicated that the compression fibre failure is a key mechanism of the final failure of impacted specimens during CAI. They add that the final failure process can be divided into two distinct phases: the evolution of the damage distributing zone near the impact damaged area and the final failure. They point also the effect of the dent contour which evolves during the CAI from a circular zone to an elliptic zone, where the major axis of the ellipse is perpendicular to the loading direction.

In this study [16,17], they compare the CAI failure mechanism to a failed notched laminate. This comparison is important because it suggests the buckling is not the only factor driving the final failure, but the propagation of a compressive fibre failure near the impacted zone should play an important role in the final failure of the laminate. This idea is going to be used in the present work and is going to allow proposing a model for the prediction of the residual strength knowing the size of the damage zone (cf. Section 6). The objective of this model is not really to predict the residual strength for a design process but to highlight the role of the compressive fibre failure on the final fracture.

In a recent paper on edge impact and CAI of stiffened composite panels, Li and Chen [13] compare effect of impact damage on T-stiffener, I-stiffener and skin. They show the effect of impact damage to the stiffener edge is more severe than that to the skin. In particular, they demonstrate the damages caused by skin impact do not affect the residual strength, contrary to the edge impacts! This result is very surprising and that does not matter the skin impact does not affect the skin residual strength, but it means that, in their case of stiffened panel, the residual strength of the whole panel is mainly carried by the one of the stiffeners. Of course, the result could be different depending on the ratio of the total load carried by the skin and by the stiffeners. But of course the study demonstrates clearly the after free edge impact vulnerability of stiffened panels.

Then the objective of the present paper, like the previous authors' edge impact study [18,19], is to study the damage scenario of the CAEI in order to improve CAEI knowledge. In particular, the main question is to found why the final failure occurs in order to give the right final failure criteria $[20,21]$. The complementarity of the different CAEI experiments carried out allows to help the physical understanding of the phenomenon.

The challenge is to study in detail the after edge impact phenomenon in order to identify the parameters that affect the residual strength after edge impact which are:

- The buckling stress.

- The strain evolution in compression direction of the two opposite laminate's faces, in order to determine the influence on the compression and the bending when the buckling appears.

- The failure force, giving the residual stress.

- The crack tracking (if possible).

3D digital image correlation (DIC) analyses have also been processed to understand the failure scenario. This way, it will be possible to improve the stringer's impact damage tolerance.

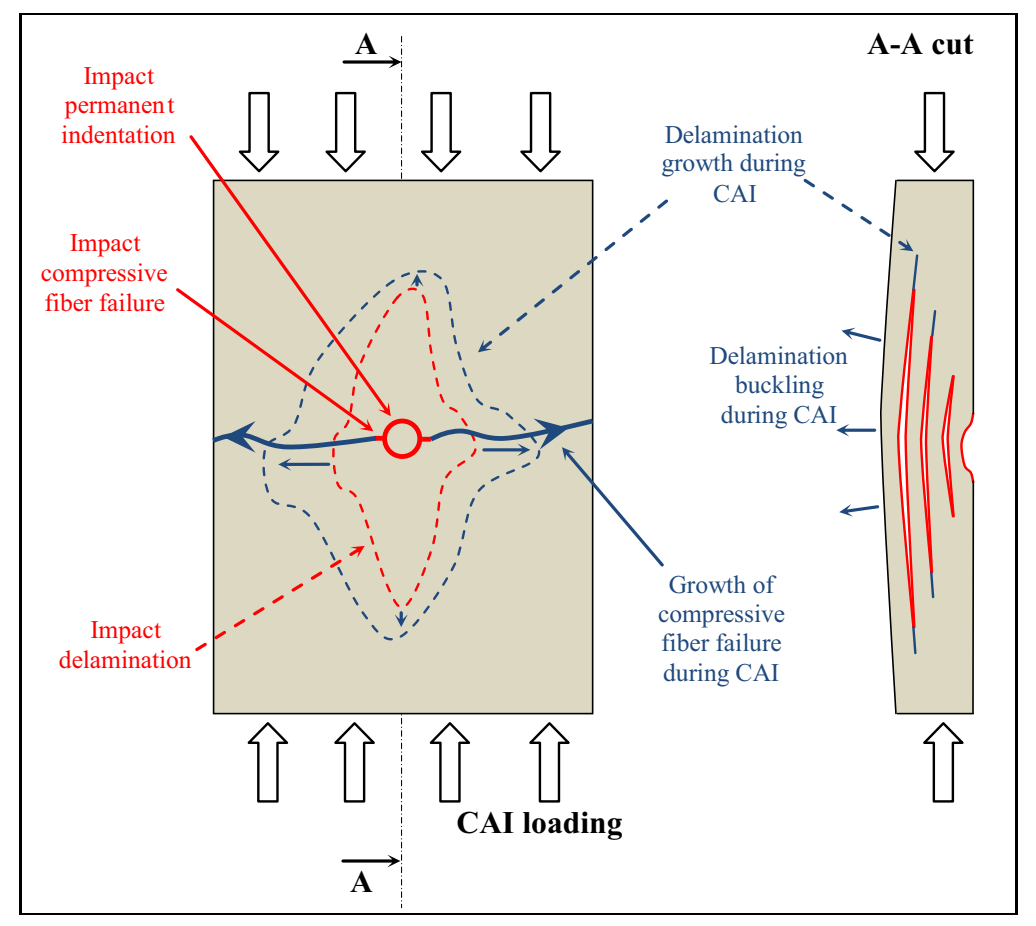

Fig. 1. Typical scenario of damage and failure of CAI test.[15] 


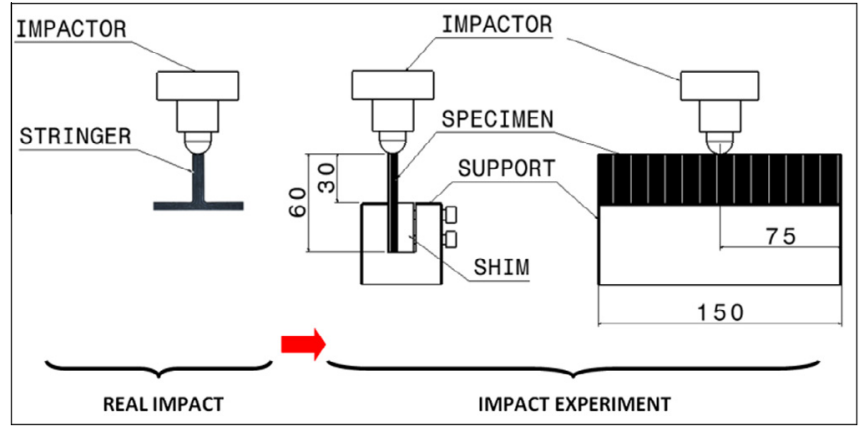

Fig. 2. Edge impact tool principle.[18]

The other objective of the present paper is to propose a test to easily study the edge impact and the CAEI without complex specimen. Indeed, the manufacturing of stiffener panels is complex and costly. Moreover high capacity machine is necessary to load the whole stiffener panel and the test is complex [13]. The proposed tests of impact and of CAEI allow to perform test with simple flat panel. Of course, the proof should be done that the tests are representative of real test on stiffener panels, this work is in progress. But in preliminary study, it allows to study the influence of a lot of parameters, such as stacking sequence, edge thickness, material, impact energy, geometry... on the residual strength of the stiffener without complex manufacturing of the whole panel.

Then the edge impact test proposed in [18] is adapted to performed CAEI on composite laminate with 4 different stacking sequences at different impact energy levels.

\section{Material}

In this study, every experiment presented has been carried out with the same laminates than the edge impact analysis [18] . The stacking sequences are representative of the current industrial needs. The specimen presents the same size than real-life stringer structure i.e. $150 \mathrm{~mm}$ long, $60 \mathrm{~mm}$ high specimen with $30 \mathrm{~mm}$ free outside boundary conditions (Figs. 2 and 6).

T700/M21 UD carbon prepreg was selected, which is a very well-known aircraft material [22], and its properties that came from standard tests are listed in Table 1. A carbon fabric woven/epoxy M21/46280 has also been used and its properties are given in Table 1.

Following four different stacking sequences have been defined:

- Stacking 1: $\left[90,45,0_{3},-45,0_{2}, 45,90,-45,0\right]_{s}, 6$ mm-thick for 24 plies.

- Stacking 2: $\left[90_{2},-45_{2}, 0_{4}, 45_{2}, 0_{2}\right]_{s}, 6$ mm-thick for 24 plies.

- Stacking 3: $\left[45_{2}, 0_{2},-45_{2}, 0_{4}, 90_{2}\right]_{\mathrm{s}}, 6 \mathrm{~mm}$-thick for 24 plies.

- Stacking 4: [Fabric woven (0/90), $\left.-45_{2}, 0_{4}, 45_{2}, 0_{2}\right]_{\mathrm{s}}, 5.6 \mathrm{~mm}-$ thick for 22 plies.

Thicknesses are consistent with the laboratory test facilities and are in agreement with the industrial ranges. These stacking sequences are oriented as $50 \%$ of the plies at $0^{\circ}$ (longitudinal direction), which matches well with industrial stacking in such stiffener

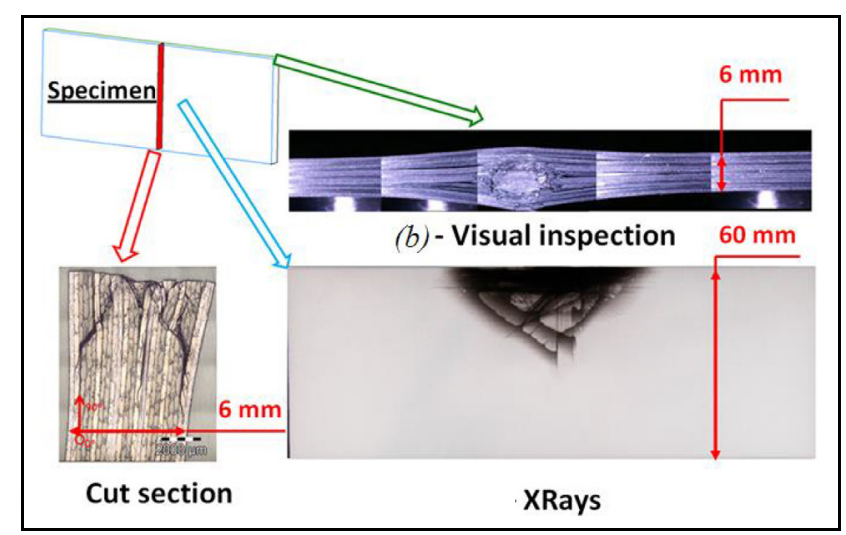

$-a-$

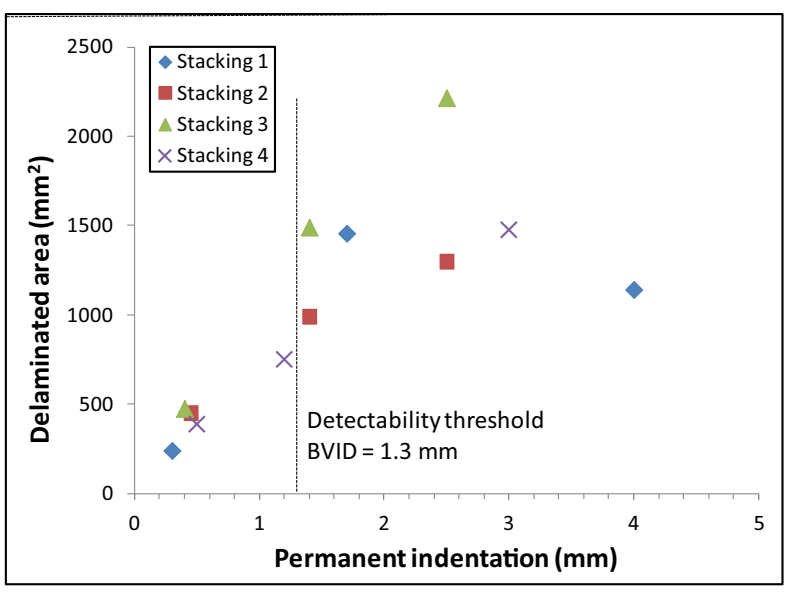

$-\mathrm{b}-$

Fig. 3. Typical post impact damage (a) and delaminated area versus permanent indentation measured after impact (b).[18]

issues. Stacking 1 is representative of an aeronautical industrial layup (symmetrical, well beaten, no delta at the interface greater than $45^{\circ}$, outside $90^{\circ}$ plies to limit $0^{\circ}$ plies damage in case of flank impact). Stacking 2 limits the number of different orientations at interfaces, which will be of greater interest in modelling and will hence shorten the numerical model development. Case 3 follows the same philosophy and has better buckling resistance due to the outside $45^{\circ}$ plies. Stacking 4 is equivalent with stacking 2 but it has a fabric woven instead of the two $90^{\circ}$ outer plies. The initial goal was damage limitation and this allows investigating the fabric woven residual strength influence.

\section{Edge Impact experiment main conclusions}

In order to help the reader understanding of this paper, the main conclusion of the edge impact experimental study [18] are presented:

Table 1

Mechanical material properties.

\begin{tabular}{|c|c|c|c|c|c|c|c|}
\hline Material & $\begin{array}{l}\text { Ply thickness } \\
(\mathrm{mm})\end{array}$ & $\begin{array}{l}\text { Longitudinal Young modulus } \\
\text { in tension }(\mathrm{GPa})\end{array}$ & $\begin{array}{l}\text { Longitudinal Young modulus in } \\
\text { compression }(\mathrm{GPa})\end{array}$ & $\begin{array}{l}\text { Transverse Young } \\
\text { modulus (GPa) }\end{array}$ & $\begin{array}{l}\text { Shear } \\
\text { modulus (GPa) }\end{array}$ & $\begin{array}{l}\text { Poisson } \\
\text { ratio }\end{array}$ & $\begin{array}{l}\text { Compressive fibre } \\
\text { failure strain }(\mu \varepsilon)\end{array}$ \\
\hline T700/M21 UD & 0.25 & 130 & 100 & 8.5 & 4.2 & 0.33 & 12,500 \\
\hline M21/46280 fabric & 0.3 & 63 & 63 & 63 & 5.1 & 0.04 & 11,000 \\
\hline
\end{tabular}




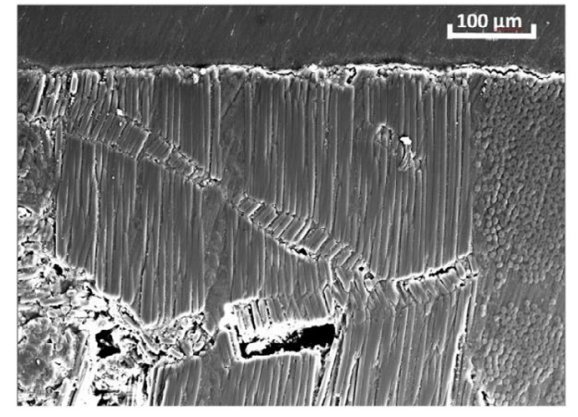

$-a-$

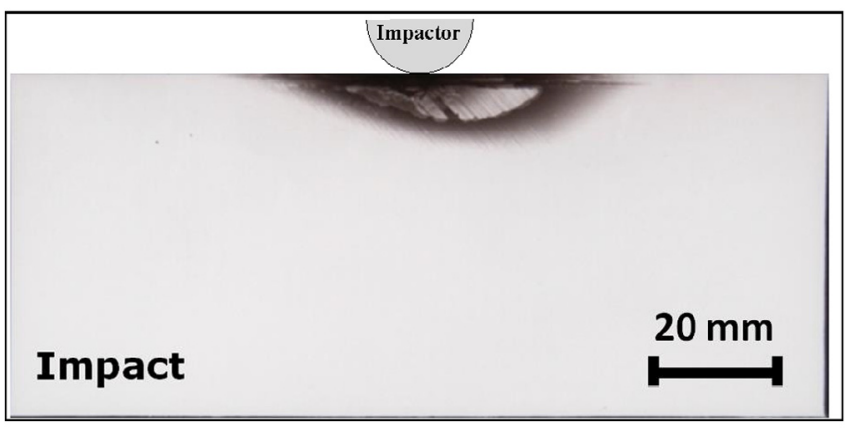

$-b-$

Fig. 4. Stacking 3 kink bands: SEM cut section after $10 \mathrm{~J}$ impact (a) and stacking 4 impact: X-rays after $20 \mathrm{~J}$ impact.

- A specific experimental test of edge impact has been designed (Fig. 2) in order to easily study the edge impact damage scenario. This test needs only flat panels contrary to real edge impact requiring the whole stiffened panel manufacturing. All tests are performed with the same hemispherical $16 \mathrm{~mm}$ diameter impactor and $2.368 \mathrm{~kg}$-weight. The specimen is clamped in a specifically designed edge impact tool (Fig. 2) and locked on half of its height with a remaining clearance of $30 \mathrm{~mm}$. The objective is to avoid fabrication of a costly stiffener which is at the same time representative of a real impact on a stiffener. In addition, it still remains consistent for the damage study preventing the damage to propagate up to the boundary conditions. The edge impact tool is composed of a steel support and a shim allowing the specimen to be locked under constant pressure. This assembly represents a housing connection (30 $\mathrm{mm}$ high of the specimen locked and $30 \mathrm{~mm}$ free under edge impact). Then the specimen presents the same size as that of a real-life stringer structure, i.e. $150 \mathrm{~mm}$ long, $60 \mathrm{~mm}$ high specimen with $30 \mathrm{~mm}$ free outside boundary conditions and is coherent with the CAEI.

- The damage after impact consists with permanent indentation under the impactor, delaminated interfaces, fibre failures and some matrix cracks (Fig. 3a). The curve of the delaminated area versus permanent indentation is plotted Fig. 3 and versus impact energy level Fig. 20b.

- If fibres are oriented in the impact direction, then kink bands due to compressive fibre failure (Fig. 4) are created just under the impactor. At the same time, impact creates classically a delaminated area just under the impact point.

- For all impact tests, irrespective of the energy level (10, 20 and $35 \mathrm{~J}$ ) and stacking sequence (1-4), the force-displacement curves have similar initial stiffness (Fig. 5). The initial stiffness can be evaluated by multiplying the contact surface of each fibre orientation by the fibre compressive failure strain, then

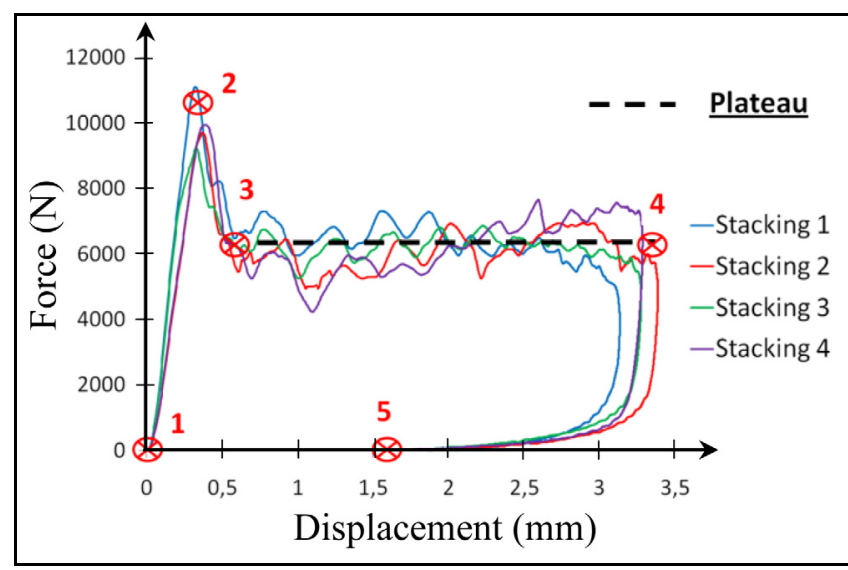

$-a-$

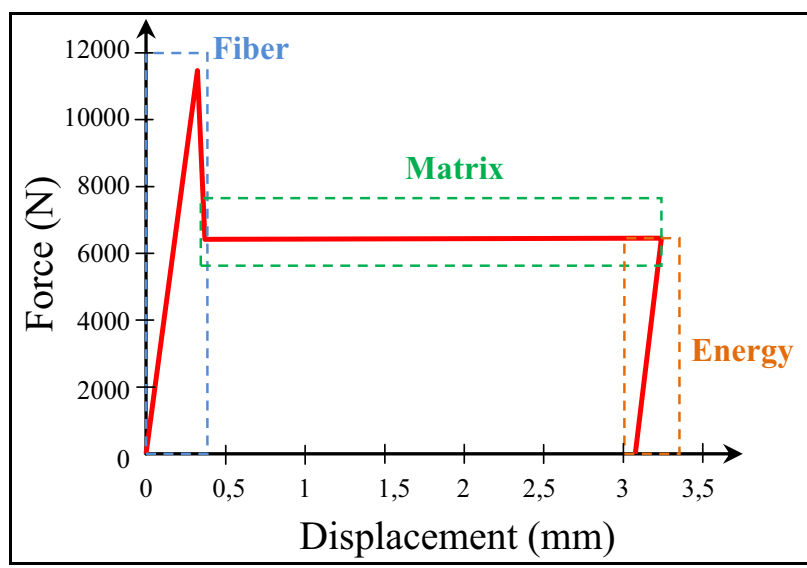

$-b-$

Fig. 5. Experimental impact curves at $20 \mathrm{~J}$ (a) and schematic impact with damage scenario (b).

the first part (point 1 to 2 ) of the curve is controlled by fibre behaviour and in particular by compressive fibre failure. The plateau of the curve (point 3 to 4 ) is similar to crushing process [23], then the second part of the curve is controlled by matrix behaviour and in particular by compressive matrix failure. And the last part of the curve (point 4 to 5), and in particular the maximum reached displacement is driven by the impact energy level.

\section{Compression after edge impact experimental set up}

To the author's knowledge, there is no existing method of CAEI. That is why CAEI experiments of this paper have been carried out with a specific method (Fig. 6) inspired from Airbus Industries Test Method $[1,2,9]$. At the same time, this experimental set up allows to perform CAEI with simple plate samples, contrary to real CAEI which needs complex stiffened panel manufacturing [13].

CAEI experiments were performed on a $400 \mathrm{kN}$ Schenck compression device at a $0.01 \mathrm{~mm} / \mathrm{min}$ imposed speed (Fig. 7) and the tests were done on damaged specimens (from edge impact study [18]) and undamaged specimens in order to determine the damage influence on the compressive residual strength.

Compression force, out of plan displacement at the specimen centre (under the impact), surface strain and displacement field of the specimen (by DIC) were measured (Figs. 7 and 8). 


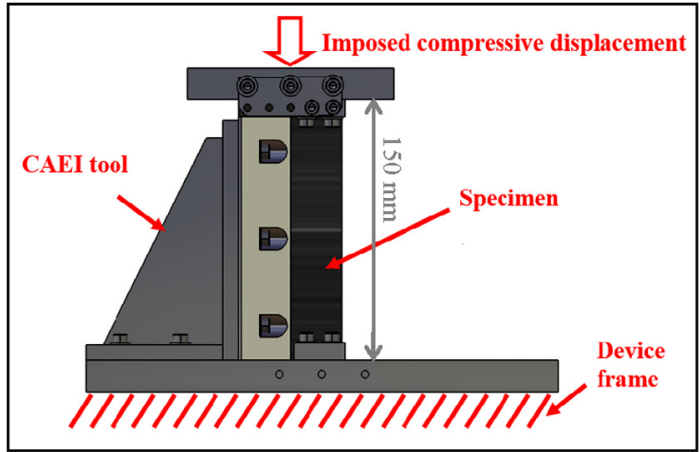

$-a-$

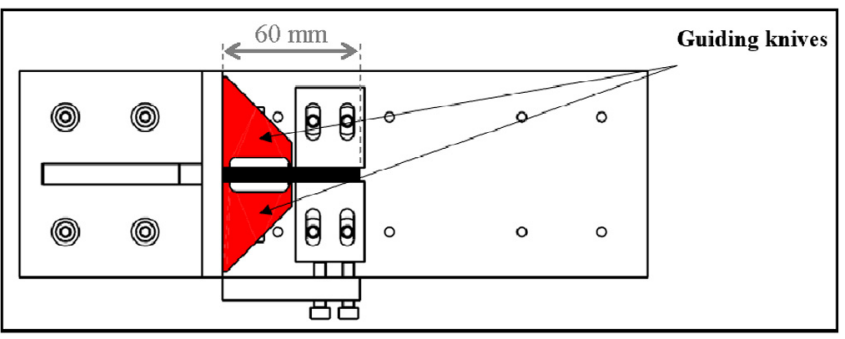

$-b-$

Fig. 6. experimental set up of CAEI: front view (a) and top view (b).

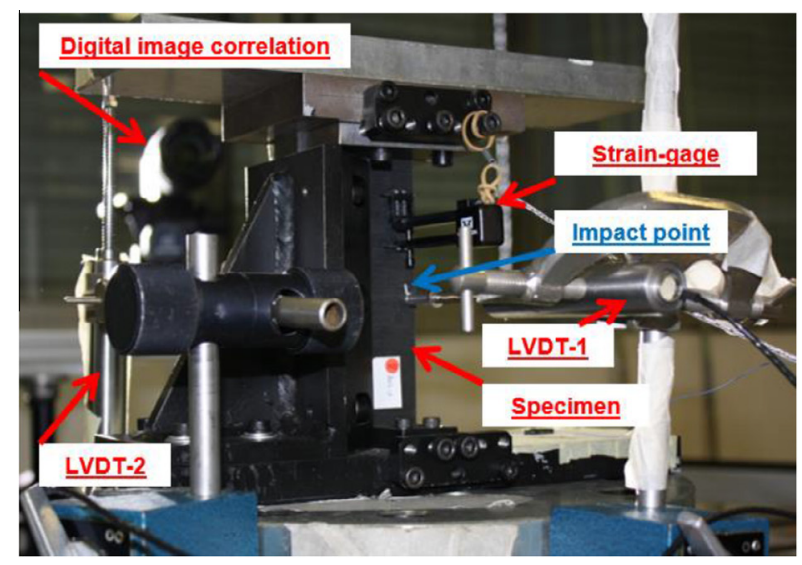

$-a-$
CAEI tool (Fig. 8) have been designed in order to simulate the same boundary conditions that a classical "stringer + skin" structure. The main goal is to realise a guide-rail type connection on the specimen that does not disturb the damage due to the edge impact. This tool is inspired from Boeing's standard BSS 7260 [24,25].

The major difference with the Boeing's standard BSS 7260 [25] is the positioning of two guiding knives (Figs. 6 and 8). These two guiding knives are made of two blades witch allow the specimen translation on the compression direction as a guide rail-type connection.

It is generally agreed to say that the CAEI is a difficult test. It is then crucial to reproduce the specimen mounting as exactly as possible. Thus, one guiding knives is fixed on an inspection table to ensure squareness with the lower support. This boundary condition is then never changed during the total experiment. The specimen is finally mounted in the CAEI tool with the help of the second guiding knife on the opposite side of the specimen for each CAEI test.

Sensors are then set in position on the specimen (Figs. 7 and 8). On one side of the specimen, LVDT- 1 is positioned $5 \mathrm{~mm}$ under the impact point and measures the out-of-plan displacement (specimen buckling). A strain gage extensometer is bonded on this side to give the longitudinal strain in the loading direction. LVDT-2 controls the loading displacement. The opposite side of the specimen is monitored by 3D DIC system in order to measure the specimen bending and the displacement and strain fields.

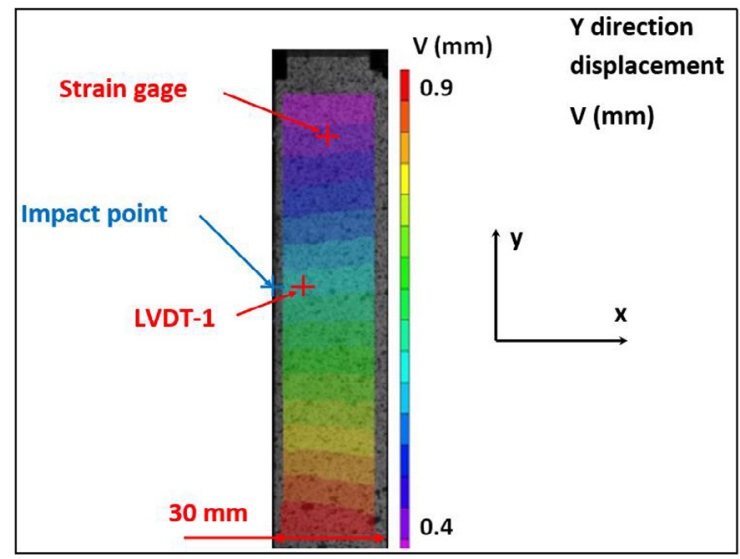

$-b-$

Fig. 7. CAEI controls (a) and pre-load check with DIC (b).

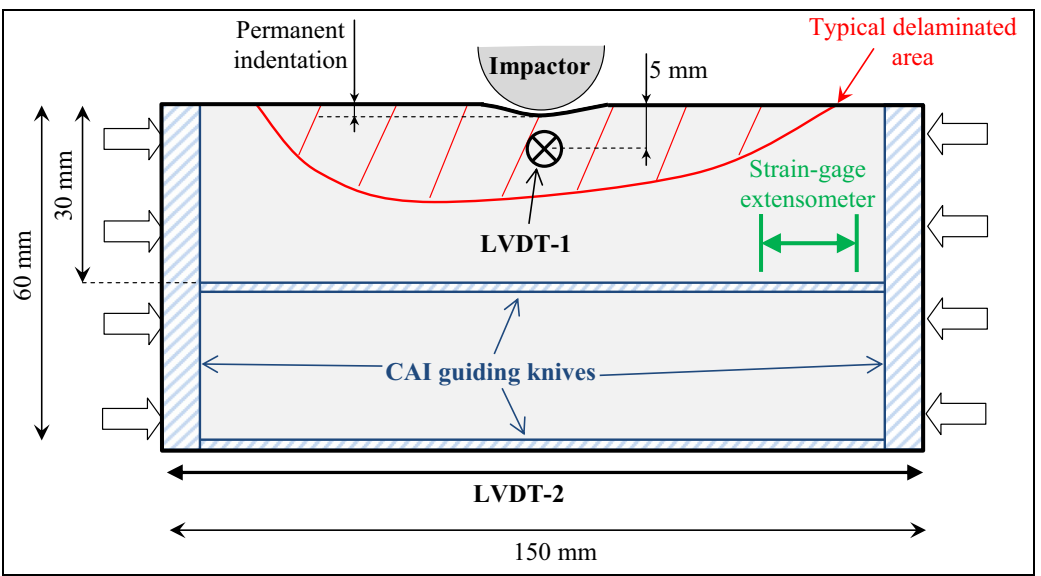

Fig. 8. Guide-rail type connection realised with guiding knives. 

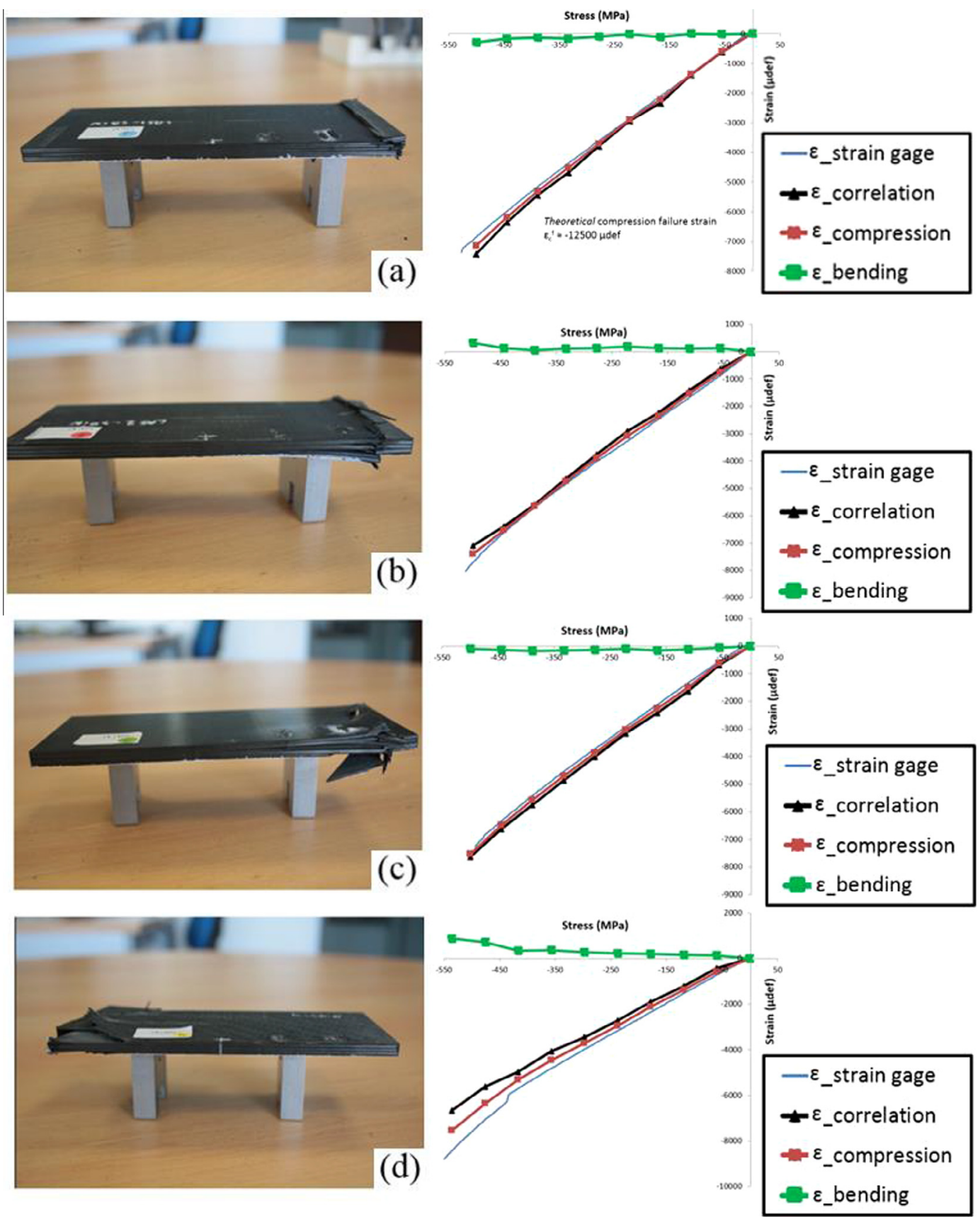

Fig. 9. Undamaged stacking 1 (a), 2 (b), 3 (c) and 4 (d) compression stress-strain curves and post mortem photos.

The specimen shape evolution is then determined thanks to the controls on both sides. In addition the difference between the two displacements at the impact point on both sides shows the opening or closing mode of the specimen.

After preliminary DIC step, the specimen is pre-loaded at $15 \mathrm{kN}$ and a calibration is made to check the displacements consistency (Fig. 7). The experiment could then be carried out and the compressive residual strength evolution after edge impact could be followed.

The compression and bending strains are determined to give the global buckling of the specimen (Fig. 9):

$$
\left\{\begin{array}{l}
\varepsilon_{\text {compression }}=\frac{\varepsilon_{\text {strain gage }}+\varepsilon_{\text {correlation }}}{2} \\
\varepsilon_{\text {bending }}=\frac{\varepsilon_{\text {strain gage }}-\varepsilon_{\text {correlation }}}{2}
\end{array}\right.
$$

The specimen displacements measured on both sides allow to detect the possible presence of local or global buckling during the CAEI [24].

\section{CAEI experiment results}

\subsection{Results from undamaged specimens}

The out-of-plan displacement field $\mathrm{w}$ is measured thanks to DIC on one side and thanks to one point displacement in the opposite side (LVDT-1). The critical buckling stress could be identified with 2 methods. First of all, with the w measurement. In theory, w is equal to 0 until buckling appears. Nevertheless, this is only true for an undamaged specimen. If the specimen is damaged, the 


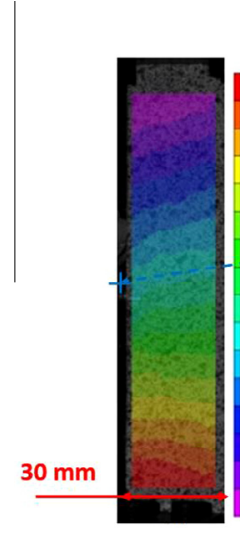

(a)

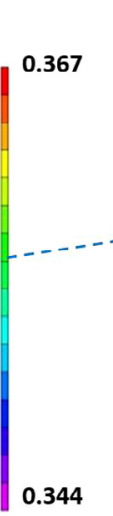

0.344

(b)

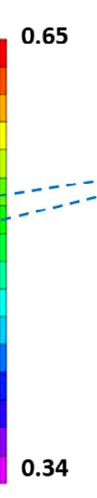

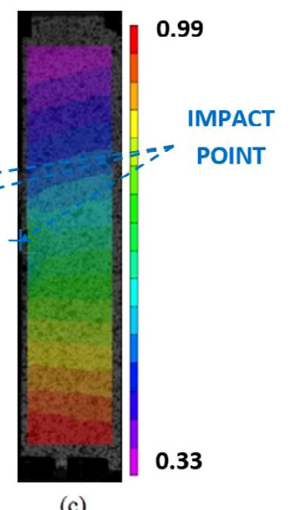

(c)
Fig. 10. Stacking 1 impacted at $20 \mathrm{~J}$ energy, filed displacement $v$ in the compression direction at $111 \mathrm{MPa}(\mathrm{a}), 333 \mathrm{MPa}$ (b) and $500 \mathrm{MPa}(\mathrm{c})$.
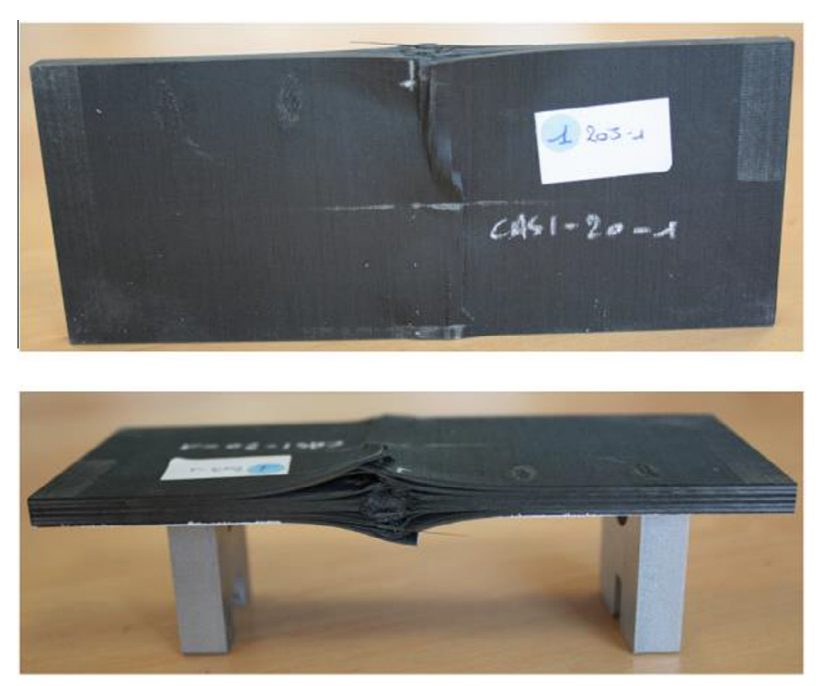

Fig. 11. CAEI failure picture of stacking 1 impacted at $20 \mathrm{~J}$.

out-of-plan displacement is more unstable and evolves during CAEI test. When buckling appears, the out-of-plan displacement grows quickly and the buckling initiation is more difficult to identify than the undamaged specimen case. That is why a second method based on the compression and bending strains evolution was used. The compression strain evolves linearly with the compression load. When the buckling initiates, the linearity is lost and a bending component appears.

First of all, Compression experiment was carried out on undamaged specimen of each stacking sequence. These experiments are the references of the damage tolerance analysis. The stacking sequence $1\left(\left[90,45,0_{3},-45,0_{2}, 45,90,-45,0\right]_{s}\right)$ is chosen to describe the study.

During the experiment, the displacement field, namely $v$, in the $y$ direction is controlled. The field displacement staying homogeneous could be observed with equivalent strain values in $x$ direction, which proves a right progression of the compression test.

No buckling clearly appears on the undamaged specimen (Fig. 9), excepted for a beginning of buckling that can be observed just before the final failure of the specimen. The after failure specimen topography shows a failure due to peening at the boundary condition location. It is also true for all the other stacking sequences. Strain evolution in the compression direction shows a relative homogeneity on the specimen surface.
The final failure happens sooner than expected. Indeed, the $0^{\circ}$ plies should be the first to break for $12,500 \mu \varepsilon$ strain (the failure strain of the T700/M21) for stacking sequences 1, 2, 3, corresponding to $750 \mathrm{MPa}$, and the fabric plies should be the first to break for $11,000 \mu \varepsilon$ strain (the failure strain of the M21/46280) for stacking sequence 4 , corresponding to $745 \mathrm{MPa}$. These values are obtained considering the final failure is due to compressive fibre failure, using a strain failure criterion, which corresponds to multiply the fibre failure strain in compression by the equivalent Young's modulus of the laminate in the loading direction (60 GPa for stackings 1, 2, 3 and $68 \mathrm{GPa}$ for stacking 4). Considering the low difference between these 2 failure stresses, $750 \mathrm{MPa}$ will be considered as the theoretical failure stress later.

The experimental failures are observed at $528 \mathrm{MPa}$ (stacking 1 ), $544 \mathrm{MPa}$ (stacking 2), $542 \mathrm{MPa}$ (stacking 3) and $539 \mathrm{MPa}$ (stacking 4). Obviously this is due to the peening failure mode at the boundary condition location. It is a classical issue of CAI experiment [26-29].

\subsection{Failure scenario of CAEI}

Then, the impacted (damaged) specimens [18] are studied and submitted to CAEI. The same displacement $v$ (Fig. 10) and strain $\varepsilon_{y y}$ analysis is carried out in order to prove a right progression of the compression test.

The failure comes hardly and propagates at the specimen centre (Fig. 11) in the impact direction (normal to the compression load).

From a quantitative point of view, the force-imposed displacement curves analysis (Fig. 12) gives interesting information. For the four stacking sequences, a progressive compressive force rising is observed, then a maximum force is reached and finally the force drops sharply. In addition, for each stacking sequence, the stiffness is similar for 10, 20 and $35 \mathrm{~J}$ impact energy level. In these curves (Fig. 12a and b), non-linear behaviour is observed at the beginning of the tests. This phenomenon is due to the classical problem of sample positioning at the test starting and should not be considered for interpretation.

On one hand, for the stacking sequences 1 and 2 (Fig. 12), the maximum compressive force reached decreases when impact energy increases. On the other hand, for the stacking sequences 3 and 4 (Fig. 12c and d), the maximum compressive force reached for 10 and $20 \mathrm{~J}$ impact energy levels is very similar and the failure force drops only for $35 \mathrm{~J}$ impact energy level. This might be due to the fact that these specific stacking sequences have $45^{\circ}$ plies (stacking 3) and fabric woven (stacking 4) plies outside laminate delaying buckling. The low number of tests carried out must be taken into account and this result handled carefully. A repeatability study will have to be realised in the future.

The very fast crack propagation cannot be followed with the actual method. But a release of dust could be observed (Fig. 13) at the impact point level a few seconds before the final failure. At the same time, a specific broken noise is heard; it indicates a possible fibre failure.

This failure is also driven by a global buckling determined with the stress-strain and stress-deflection curves (the deflection is the out-of-plan displacement) (Fig. 14). It could be noted that positive deflections (on one hand from LVDT-1, and from DIC on the other hand) mean a swelling of the specimen. The positive sum of these two deflections represents a growth of the specimen thickness. The buckling appears lately and the failure is explosive. It is due to the instability created by the edge impact damage, whatever the impact energy and the stacking sequence.

Swelling appears early during the CAEI and a specific behaviour of the specimen can be observed during CAEI. Indeed, a bending effect of all the specimens happens but the centre of specimen 


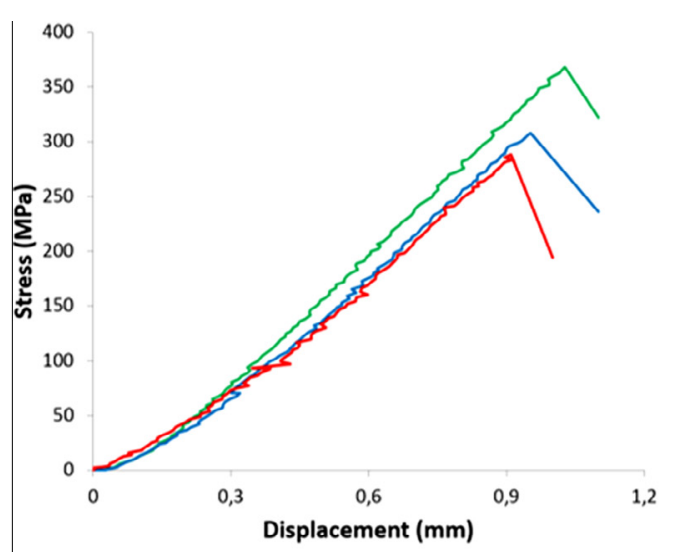

(a)

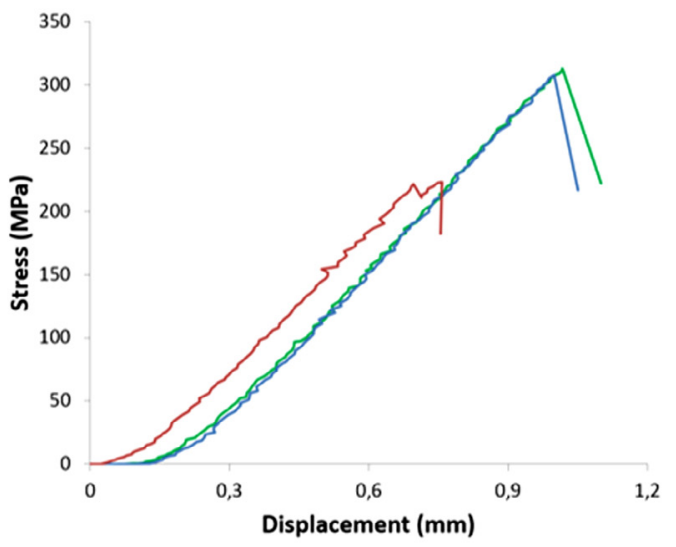

(c)

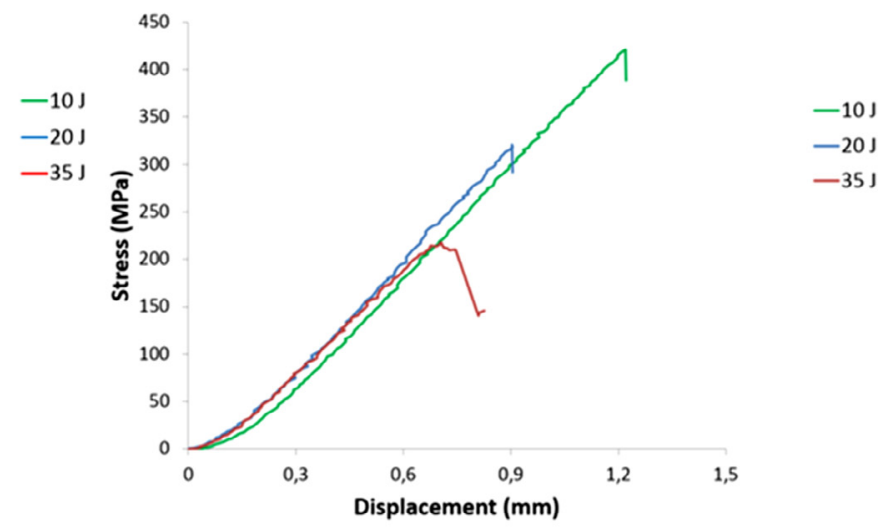

(b)

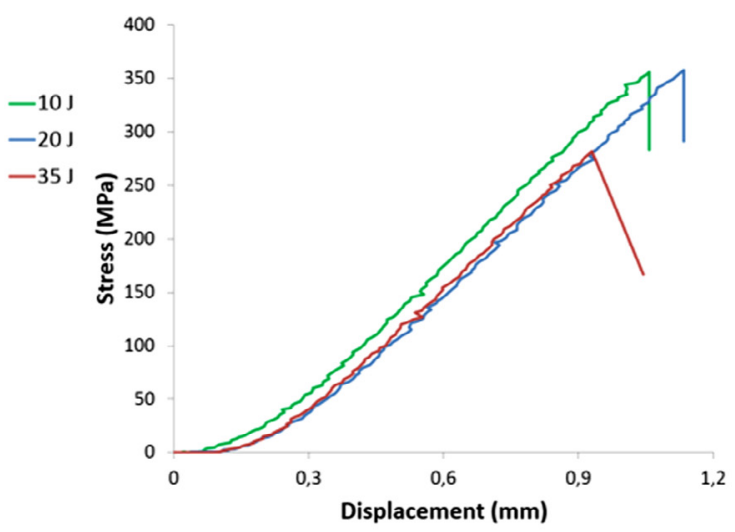

(d)

Fig. 12. CAEI of stackings 1 (a), 2 (b), 3 (c) and 4 (d): stress versus displacement curves.

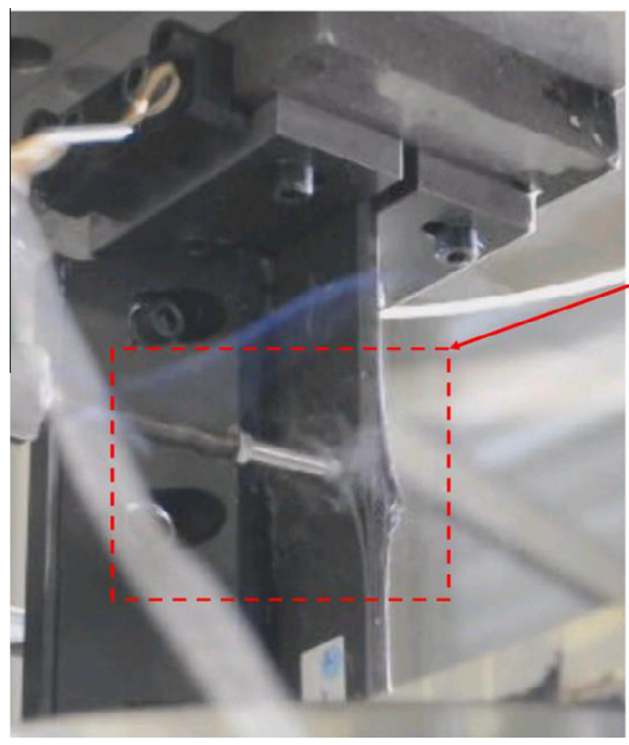

DUST

Fig. 13. Stacking 1 impacted at $20 \mathrm{~J}$ energy, release of dust just before final failure.

(at the impact point level) reacts in the opposite direction (Fig. 15). Nevertheless, it can be noticed that $W=0$ matches the after edge impact shape and not the undamaged shape.

The specimens' thickness grows at the impact point level (Fig. 15b). Local buckling of the delaminated area and compressive fibre failure (normal to the load) coexist and it is difficult to determine which one initiates the final failure, although the impact point area closure suggests that the fibre failure propagation drives the final failure (Fig. 15c). Obviously, the specimen global buckling observed may overload the crack and starts its propagation sooner.

\subsection{Quantitative experimental results of CAEI}

Finally, the residual failure stress, the buckling initiation (Fig. 16) and the residual failure strain (Fig. 17) of each stacking sequence and each impact energy level could be represented in order to summarize the edge impact residual strength.

It can be noticed, the residual failure stress of the undamaged specimen (Fig. 16) is not representative. The values are given for information because the undamaged specimens have failed earlier than expected because of peening. The experiments on undamaged specimen were carried out to verify the test parameters. To be more specific, we would like to check if the buckling appears later than the failure for the non-impacted specimen. Thus we can confirm that, for the CAEI test, the final failure of the impacted specimen is due to the impact damage and not because of the global buckling. Similarly, the undamaged strain failure values are not representative because the undamaged specimens have failed earlier than expected because of peening (Fig. 17).

Nevertheless, these results must be taken with precaution due low number of tests carried out, and a repeatability study will have to be done.

The impact damage effect is very strong for all stacking sequences and all impact energy levels. It reduces the residual 


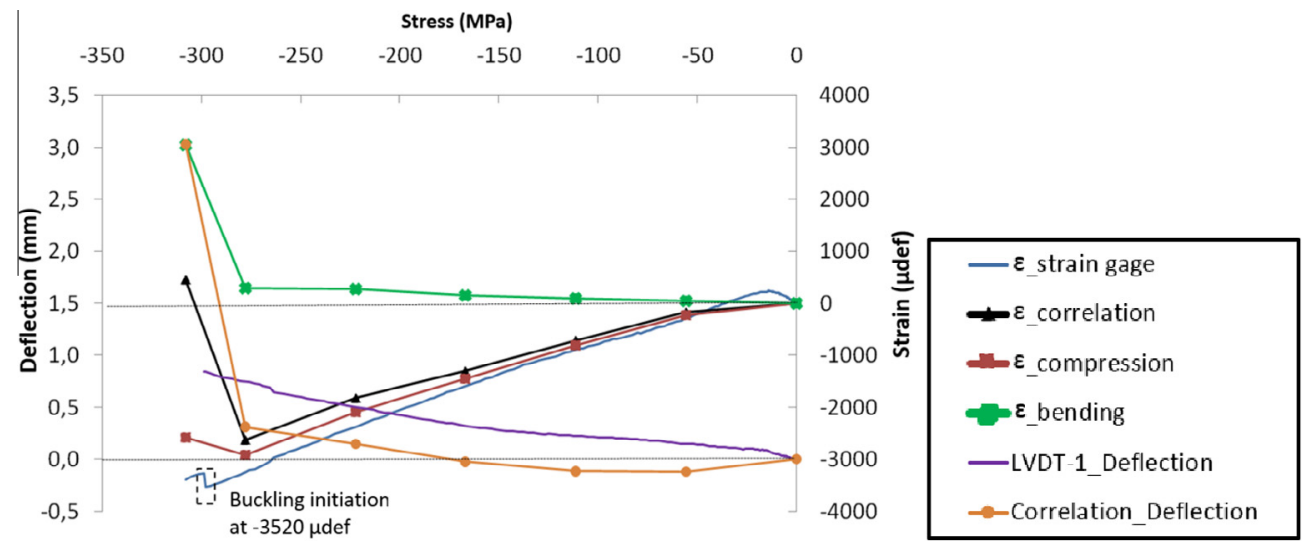

Fig. 14. Stacking 1 impacted at $20 \mathrm{~J}$ energy, stress-strain and stress-deflection curves.

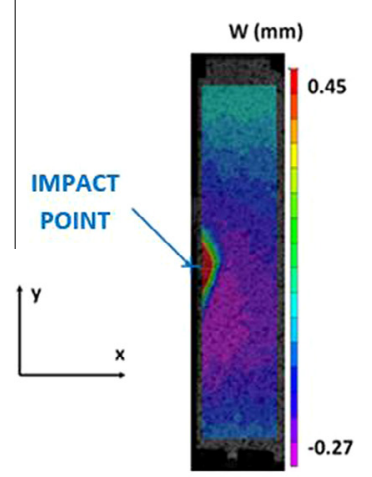

(a)

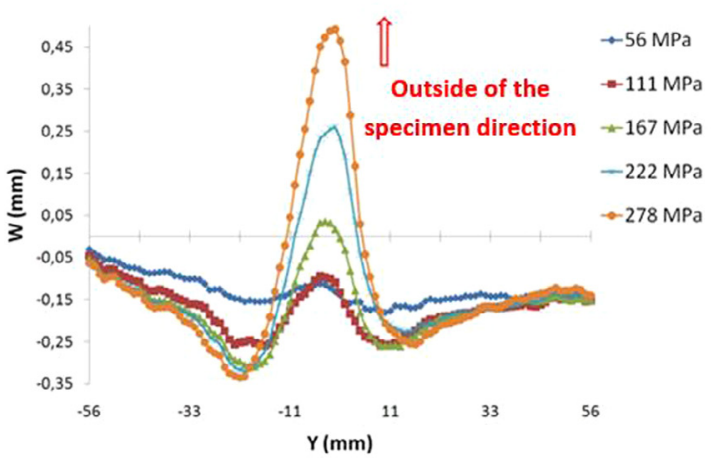

(b)

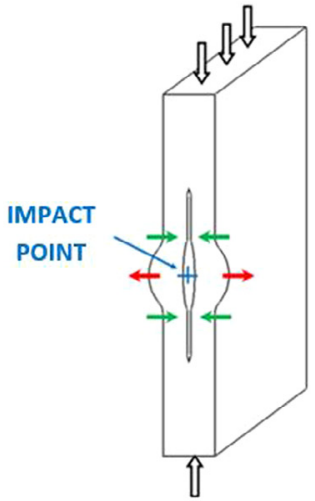

(c)

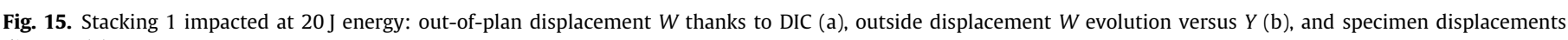
diagram (c).

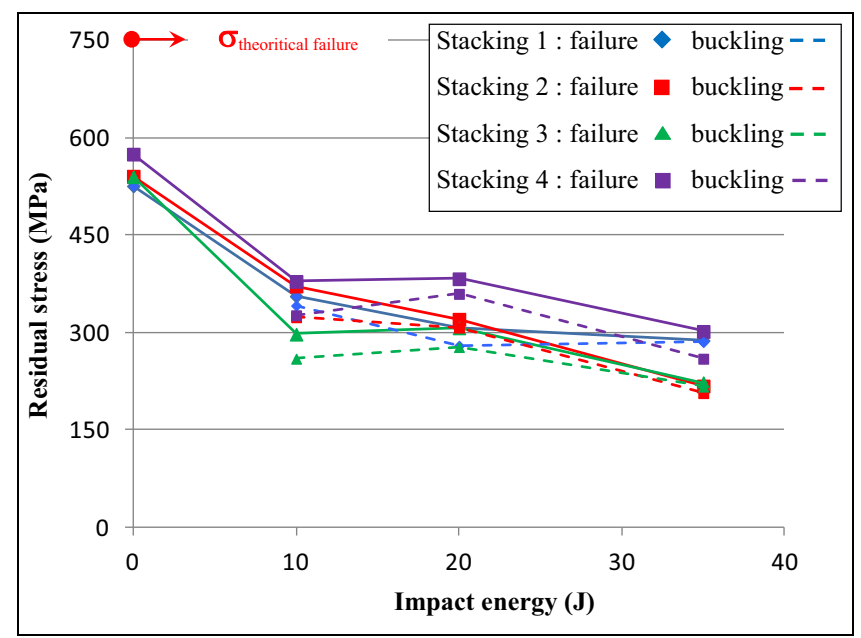

Fig. 16. Residual stress versus impact energy level.

strength of about $50 \%$ for $10 \mathrm{~J}$ impact, $55 \%$ for $20 \mathrm{~J}$ impact and $65 \%$ for $35 \mathrm{~J}$ impact (compared with the theoretical failure stress) on average for the 4 stackings. There is no real effect of the draping sequence, even if the stacking 4 seems a little bit better than the other three.

In order to study the impact damage tolerance of stiffener, it is important to evaluate the detectability of the damage. Then the

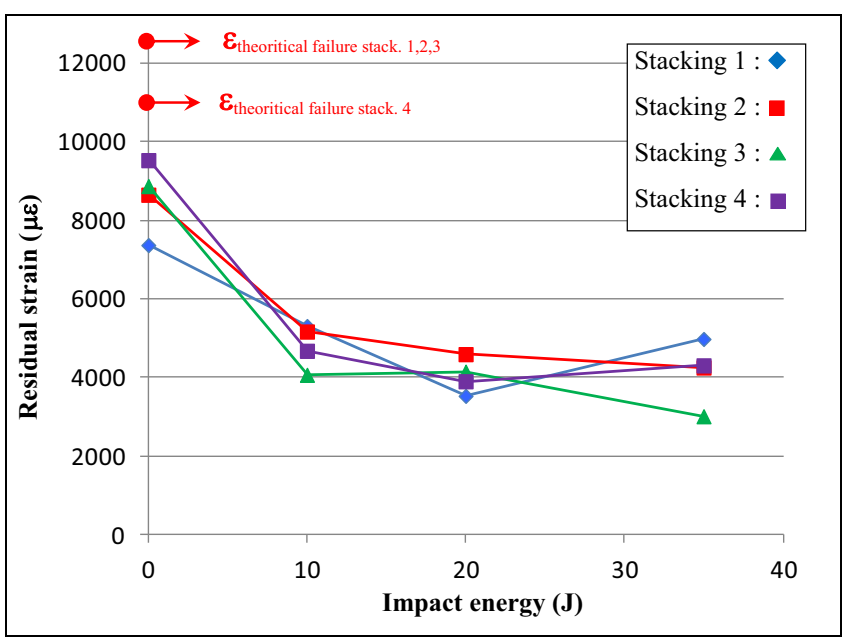

Fig. 17. Residual strain versus impact energy level.

residual strength is finally plotted versus the two parameters used to detect damage: the permanent indentation (the dent depth let by impact) and the maximum crack length (the crack length let by the impact at the edge laminate) (Fig. 18).

It is very interesting to note that stacking 1 , representing an aeronautical industrial layup, could remain undetectable for a $10 \mathrm{~J}$ impact energy level. Indeed, its permanent indentation and 


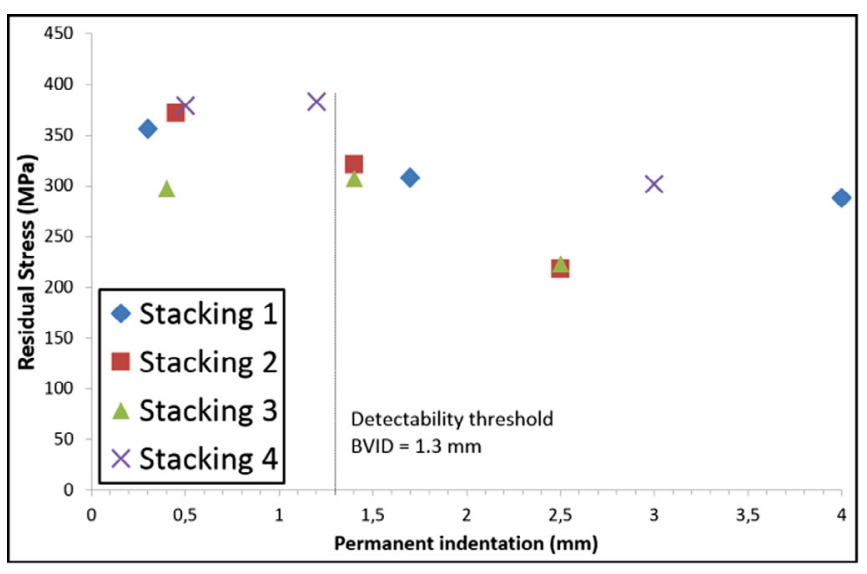

$-a-$

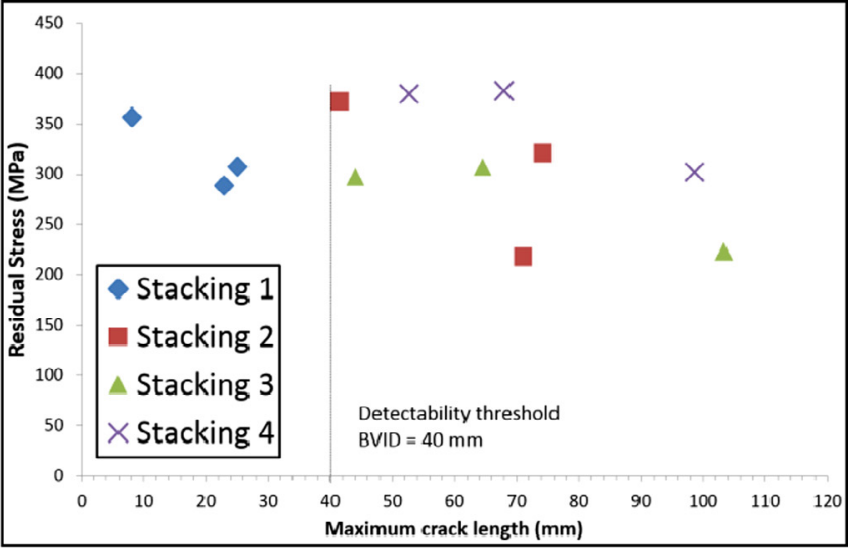

-b-

Fig. 18. Edge impact residual stress versus permanent indentation (a) and maximum crack length (b).

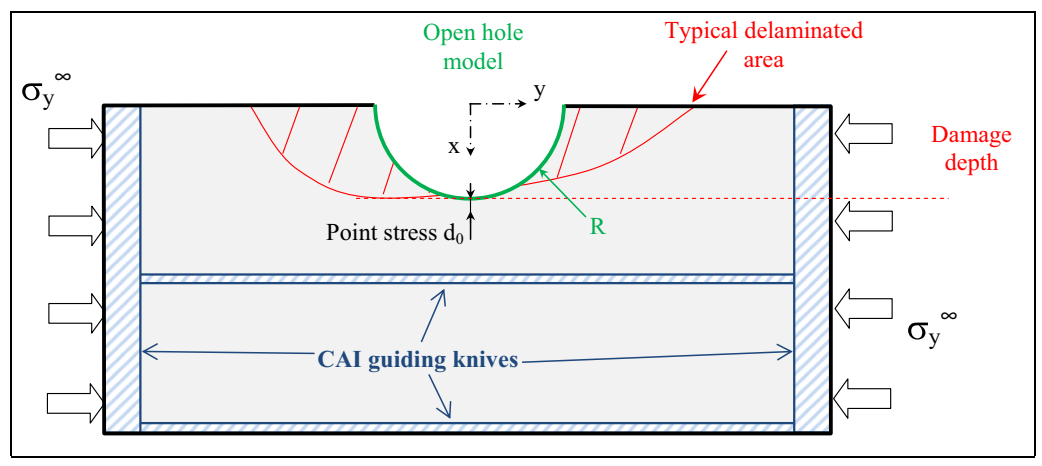

Fig. 19. Principle of the open hole model.

its maximum crack length are under BVID thresholds [3,30]. Stacking sequence 2 should also be considered undetectable for a $10 \mathrm{~J}$ impact energy level with its maximum crack length measured just on the BVID threshold frontier. The problem is that these specimens lost half of theirs compression strength (Fig. 18) proving that edge impact causes massive damage to composite structures.

For a BVID edge impact, the structure loses about between $60 \%$ (stackings $1,2,3$ ) and 50\% (stacking 4 ) of its residual compression properties even for small energy level. Indeed the first detectable impact energy is $20 \mathrm{~J}$ for stackings $1,2,3$ and $10 \mathrm{~J}$ for stacking 4 . Once more time, the stacking sequence 4 seems a little bit better than the other three.

\section{CAEI discussion and modelling}

One of the objectives of this study is to determine the damage scenario of the CAEI and in particular to determine what type of impact damage most affects the residual strength. On one hand, a buckling of the damaged zone is always observed just before the final failure (Fig. 14), and might suggest the buckling has a major role on final failure. On another hand, the release of dust just before the final failure (Fig. 13) might suggest the compressive fibre failure has a major role on final failure. In fact it is difficult to conclude and these 2 phenomena should be strongly linked.

For discussion, an open hole design has been applied in order to compare the loss of residual strength obtained after edge impact, to these ones obtained with an open hole. The chosen model of open hole is a classic model: the point stress approach [31]. Its consists to evaluate the stress concentration using analytical approach and to use the obtained stress at a given distance of the hole $d_{0}$ (Fig. 19), which is named the point stress distance.

If the problem is considered symmetric, the plate size infinite and the laminate are supposed as an orthotropic material, the stress concentration is (Fig. 19):

$$
\begin{aligned}
\sigma_{y}(x, y=0)= & \frac{\sigma_{y}^{\infty}}{2}\left[2+\left(\frac{R}{x}\right)^{2}+3 \cdot\left(\frac{R}{x}\right)^{3}-\left(K_{T}^{\infty}-3\right)\right. \\
& \left.\cdot\left(5 \cdot\left(\frac{R}{x}\right)^{5}-7 \cdot\left(\frac{R}{x}\right)^{7}\right)\right]
\end{aligned}
$$

where $\sigma_{y}{ }^{\infty}$ is the stress imposed to infinity, $R$ is the hole radius, $x$ is the local coordinate (varying from $R$ to infinity) defined in Fig. 19 and $K_{T}^{\infty}$ is the stress concentration factor defined by:

$K_{T}^{\infty}=\frac{\sigma_{y}(x=R, y=0)}{\sigma_{y}^{\infty}}=1+\sqrt{2 \cdot \sqrt{\frac{E_{y}}{E_{x}}-v_{y x}}+\frac{E_{y}}{G_{x y}}}$

where $E_{x}\left(E_{y}\right)$ is the equivalent Young modulus in the $x(y)$ direction, $v_{y x}$ is the equivalent Poisson's ratio and $G_{x y}$ is the equivalent shear modulus of the laminate.

Afterwards, the point stress considers the stress concentration factor at a distance $d_{0}$ of the hole:

$K_{T}^{0}=\frac{\sigma_{y}\left(x=R+d_{0}, y=0\right)}{\sigma_{y}^{\infty}}$ 


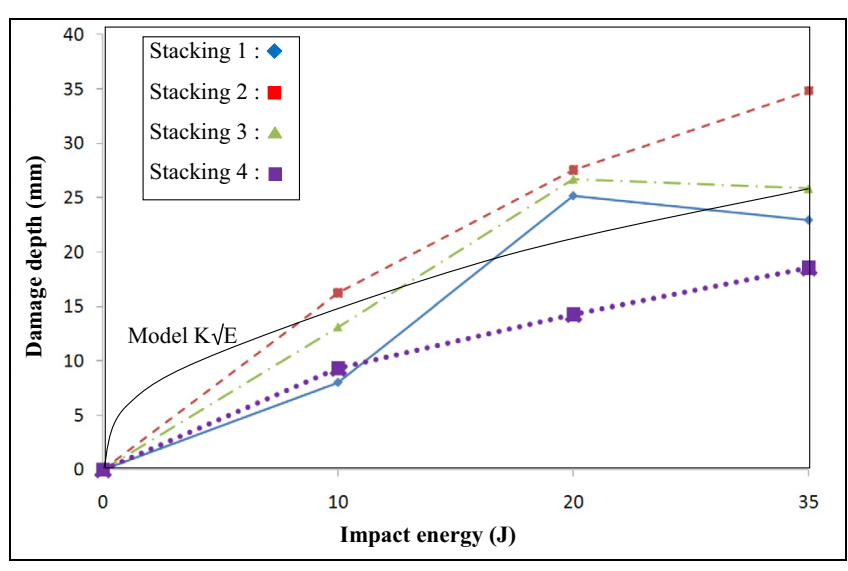

$-a-$

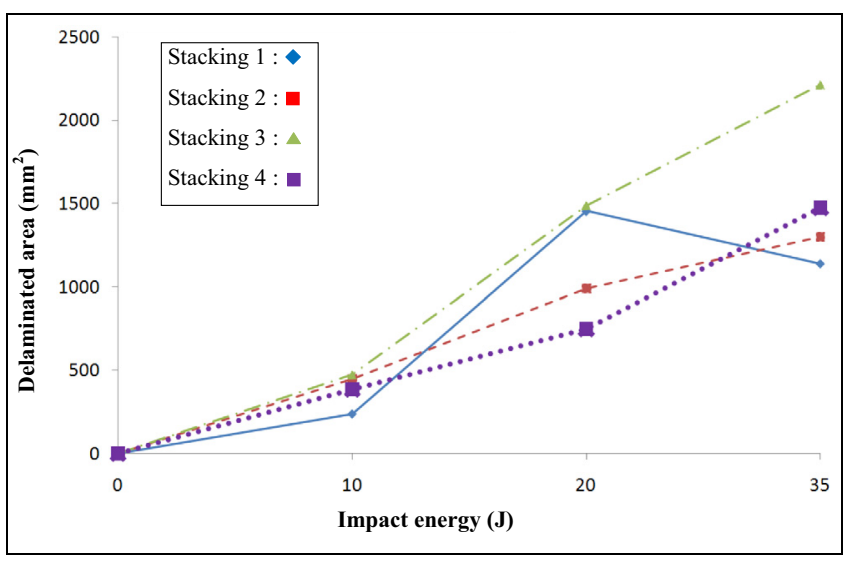

$-\mathrm{b}-$

Fig. 20. Damage depth (a) and delaminated area (b) versus impact energy.

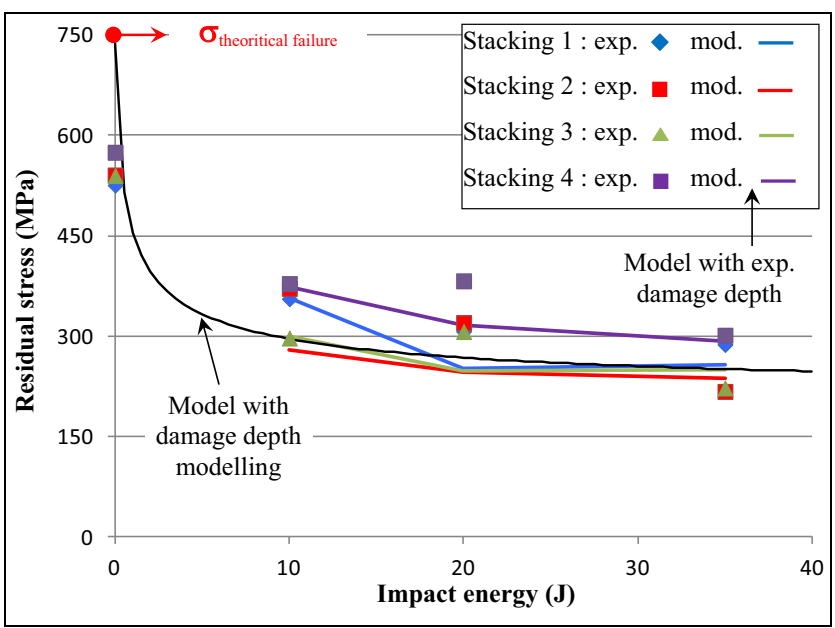

Fig. 21. Residual stress versus impact energy obtained with experiment and open hole model.

Typical values of $d_{0}$ are between 1 and $2 \mathrm{~mm}$, and $1.5 \mathrm{~mm}$ $[32,33]$ has been chosen for this study. The last parameter to determine is the hole radius which is considered equal to the damage depth measured by X-rays after impact. The damage depth has been plotted in Fig. 20a for the 4 stacking sequences and the 3 impact energy levels. These values are used to evaluate the hole radius of the open hole model. Of course the proposed model is only a model done to better understand the failure scenario and not really to predict the residual strength. In particular the real impact damage is clearly not a semi-circle and at the same time the residual resistance of the impact damage zone is clearly higher than a hole. This idea of open hole model is similar to the model proposed by Chen et al. [17] for flat panels.

To give an idea of the stress concentration factor, $K_{T}^{0}$ equals 2.8 for stackings $1,2,3$ and 2.9 for stacking 4 , for a typical damage depth of $20 \mathrm{~mm}$, and $K_{T}^{\infty}$ equals 3.8 for stackings $1,2,3$ and 4 for stacking 4 . The difference between the stacking sequences is due to the value of the equivalent Young modulus. Moreover, the $d_{0}$ influence is not so high, because for realistic values between 1 and $2 \mathrm{~mm}, K_{T}^{0}$ for stackings $1,2,3$ is between 2.6 and 3.1 (with $R=20 \mathrm{~mm}$ ).

Afterwards, the failure stress is evaluated dividing the theoretical failure stress of the non-impacted specimen by the stress coefficient factor $K_{T}^{0}$. The residual stress, obtained with the open hole model, is compared to experiments in Fig. 21. The failure stress is obtained using the measured damage depth for each stacking sequence and each impact energy. In spite of the model simplicity, a very good agreement is found.

Finally, in order to extrapolate the model to other impact energy levels, a model of the damage depth is needed. For example, for the 3 stacking sequences $1,2,3$, a square model fits relatively well the experiments (Fig. 20a):

damage depth $=K \cdot \sqrt{E}$

with $K=4.3$ if damage depth in millimetre and $E$ in joule. This model is plotted in Fig. 21 and fits very well the experimental results. Once more time, the objective of this model is only to better understand the experiments and not to predict the residual strength. In particular the model allows to highlight the very high loss of residual strength for low impact energy levels: even a little hole induces a high stress concentration factor.

The good agreement of the open hole model seems to confirm the major role of the compressive fibre failure in the final failure. In particular, the length of the delaminated area (in the $y$ direction of Fig. 19) does not seem have effect on the failure stress, contrary to the damage depth (in the $x$ direction of Fig. 19). This result is coherent with the propagation of the dent contour which evolves during the CAI from a circular zone to an elliptic zone, (where the major axis of the ellipse is perpendicular to the loading direction) observed in particular by Chen et al. $[16,17]$. Moreover, contrary to the case of impact of flat panels, where the compressive fibre failure under the impactor is not always evident, the compressive fibre failure is clearly seen very early during the CAEI test (Fig. 4a and 5). In other words, the high stiffness of the laminate (Fig. 5), submitted to edge impact, should induce a zone strongly damaged under the impactor, including in particular compressive fibre failures, which should propagate during the CAEI.

\section{Conclusion}

An experimental test set up has been designed to easily study the edge impact and the CAEI without complex specimen. It avoids the complex manufacturing of stiffener panels and avoids the use of high capacity machine. The proof should be done that the tests are representative of real tests on stiffener panels, but the first results are promising.

Then CAEI experiments have been performed on damaged and undamaged specimens in order to determine the impact damage influence on the compressive residual strength of four stacking sequences. 3D DIC analysis has also been processed to understand the failure scenario. The main conclusions of the CAEI experimental study are presented: 
- Every CAEI experiment realised in this study show brutal crack propagation normal to the compression loading direction from the impact point. The hypothesis could be made that it is a crack due to $0^{\circ}$ plies' compressive fibre failure.

- Edge impact energy level and stacking sequence have a relatively low influence on the residual strength or on the global buckling initiation that drops sharply for small edge impact energy level. The experimental behaviour seems binary and edge impact causes an important drop of the residual compression properties even for small energy level. Thus, for a BVID edge impact, the structure losses between 50\% (stacking 4) and $60 \%$ (stackings $1,2,3$ ) of its compression strength. It is difficult to recommend a stacking more than another, even if the stacking 4 with a fabric outside of laminate seems a little bit better.

To conclude, it seems that compression fibre failure propagation plays a major role in the mechanism that drives the laminate residual strength after edge impact. The very good correlation of an open hole model with the "point stress" seems confirm this hypothesis. Thus, this study proposes a unique CAEI experimental method and initiates new developments in design and optimisation of composite structures under edge impact.

\section{References}

[1] Abrate S. Impact on composite structures. Cambridge Press, University; 1998.

[2] Hull D, Shi YB. Damage mechanism characterization in composite damage tolerance investigations. Compos Struct 1993;23(2):99-120.

[3] Rouchon J. Fatigue and damage tolerance aspects for composite aircraft structures. In: Proceedings of ICAF symposium, Delft.

[4] Kaddour AS, Hinton M. The second world-wide failure exercise (WWFE-II) Part B: Evaluation of theories for predicting failure in polymer composite laminates under 3-D states of stress: comparison with experiments. In: Proceedings of the 19th international conference on composite materials (ICCM/19), Montréal, Canada.

[5] Kaddour AS, Hinton M. Evaluation of theories for predicting failure in polymer composite laminates under 3-D states of stress: Part A of WWFE-II. In: Proceedings of the 19th international conference on composite materials (ICCM/19), Montréal, Canada.

[6] Esrail F, Kassapoglou C. An efficient approach to determine compression after impact strength of quasi-isotropic composite laminates. Compos Sci Technol 2014;98:28-35.

[7] Greenhalgh E, Meeks C, Clarke A, Thatcher J. The effect of defects on the performance of post-buckled CFRP stringer-stiffened panels. Compos A Appl Sci Manuf 2003;34(7):623-33.

[8] Nyman T, Bredberg A, Schon J. Equivalent damage and residual strength for impact damaged composite structures. J Reinf Plast Compos 2000;19 (6):428-48.

[9] Rhead AT, Butler R. Compressive static strength model for impact damaged laminates. Compos Sci Technol 2009;69(14):2301-7.
[10] Soutis C, Smith FC, Matthews FL. Predicting the compressive engineering performance of carbon fibre-reinforced plastics. Compos A Appl Sci Manuf 2000;31:531-6.

[11] Malhotra A, Guild FJ, Pavier M. Edge impact to composite laminates Experiments and simulations. J Mater Sci 2008:43(20):6661-7.

[12] Rhead AT, Marchant D, Butler R. Compressive strength of composite laminates following free edge impact. Compos A Appl Sci Manuf 2010;41(9):1056-65.

[13] $\mathrm{Li} \mathrm{N}$, Chen $\mathrm{PH}$. Experimental investigation on edge impact damage and compression-after-impact behavior of stiffened composite panels. Compos Struct 2015. http://dx.doi.org/10.1016/i.compstruct.2015.11.060.

[14] Breen C, Guild F, Pavier M. Impact damage to thick carbon fibre reinforced plastic composite laminates. J Mater Sci 2006;41:6718-24.

[15] Rivallant S, Bouvet C, Abi Abdallah E, Broll B, Barrau J-J. Experimental analysis of CFRP laminates subjected to compression after impact: The role of impactinduced cracks in failure. Compos Struct 2014;111:147-57.

[16] Chen P, Shen Z, Wang JY. Prediction of the strength of notched fiber-dominated composite laminates. Compos Sci Technol 2001;61(9):1311-21.

[17] Chen P, Shen Z, Wang JY. A new method for compression after impact strength prediction of composite laminates. J Compos Mater 2002.

[18] Ostré B, Bouvet C, Lachaud F, Minot C, Aboissiere J. Edge impact damage scenario on stiffened composite structure. J Compos Mater 2014.

[19] Ostré B, Bouvet C, Minot C, Aboissière J. Edge impact modeling on stiffened composite structures. Compos Struct 2015;126:314-28.

[20] Hongkarnjanakul N, Bouvet C, Rivallant S. Validation of low velocity impact modelling on different stacking sequences of CFRP laminates and influence of fibre failure. Compos Struct 2013;106:549-59.

[21] Rivallant S, Bouvet C, Hongkarnjanakul N. Failure analysis of CFRP laminates subjected to compression after impact: FE simulation using discrete interface elements. Compos A Appl Sci Manuf 2013;55:83-93.

[22] Bouvet C, Rivallant S, Barrau J-J. Low velocity impact modeling in composite laminates capturing permanent indentation. Compos Sci Technol 2012;72 (16):1977-88.

[23] Israr H, Rivallant S, Barrau J-J. Experimental investigation on mean crushing stress characterization of carbon-epoxy plies under compressive crushing mode. Compos Struct 2013;96:357-64.

[24] AITM1-0010 Airbus Test Method. Fibre reinforced plastics: determination of compression strength after impact; 2005.

[25] BSS-7260 The Boeing Company. Boeing specification support standard. Advanced composite compression tests; 1998.

[26] De Freitas M, Reis L. Failure mechanisms on composite specimens subjected to compression after impact. Compos Struct 1998;42:365-73.

[27] Khondker OA, Leong KH, Herszberg I, Hamada H. Impact and compressionafter-impact performance of weft-knitted glass textile composites. Compos A 2005.

[28] Petit S, Bouvet C, Bergerot A, Barrau J-J. Impact and compression after impact experimental study of a composite laminate with a cork thermal shield Compos Sci Technol 2005;67(15-16):3286-99.

[29] Zhou G. Compressive behaviour of large undamaged and damaged thick laminated panels. Compos Struct 1997;38(1-4):589-97.

[30] Thomas M. Study of the evolution of the dent depth due to impact on carbon epoxy laminates, consequences on impact damage visibility and on in service inspection requirements for civil aircraft composite structures. In: MIL-HDBK 17 meeting, Monterey, California, USA.

[31] Whitney J, Nuismer R. Stress fracture criteria for laminated composites containing stress concentrations. J Compos Mater 1974;8:253-65.

[32] Tan SC. Stress concentrations in laminated composites. CRC Press; 1994.

[33] Hochard C, Lahellec N, Bordreuil C. A ply scale non-local fibre rupture criterion for CFRP woven ply laminated structures. Compos Struct 2007;80:321-6. 